\title{
The precursory earthquake swarm in Greece
}

\author{
Frank Evison ( $\left.{ }^{1}\right)$ and David Rhoades $\left({ }^{2}\right)$ \\ (1) Institute of Geophysics, Victoria University of Wellington, Wellington, New Zealand \\ (2) Institute of Geological and Nuclear Sciences, Lower Hutt, New Zealand
}

\begin{abstract}
The Hellenic subduction region displays the same precursory swarm phenomenon as has been found in comparable regions of New Zealand and Japan. In the earthquake catalogue of the Aristotle University of Thessaloniki, 10 past sequences of precursory swarms and related major mainshock events have been identified. These correlate, in respect of location, magnitude and time, with the 9 sequences previously identified in New Zealand, and 9 in Japan, bringing the total of sequences to 28 , and the totals of related events (allowing for clustering) to 56 precursory swarms and 42 mainshock events. The results add strength to the hypothesis that swarms are longrange predictors of mainshock events. A close similarity between the swarm and aftershock magnitudes in a given sequence is also confirmed in Greece, supporting the proposal that swarms are an integral part of the seismogenic process in subduction regions. Further, the modelling of swarms as part of an overall increase in seismicity, the onset of which marks the onset of seismogenesis, is well illustrated from past sequences in Greece. Formal tests are being carried out in Greece, in parallel with New Zealand and Japan, to ascertain the performance of the hypothesis as a basis for long-range synoptic forecasting.
\end{abstract}

Key words precursory swarm - seismogenesis earthquake prediction - Hellenic arc

\section{Introduction}

Fluctuations of seismicity in time and space have often been observed before major earthquakes. They were among the types of precursory phenomena compiled by Rikitake (1979), who found a strong but non-predictive relation between precursor time (i.e. the interval between precursor and major earthquake) and mainshock magnitude. Precursory seismicity patterns were discussed in detail by Kanamori (1981). For most such patterns, as with other types of precursor, research is still evidently at

Mailing address: Prof. Frank F. Evison, Institute of Geophysics, Victoria University of Wellington, P.O. Box 600 , Wellington, New Zealand: e-mail: Frank.Evison@vuw.ac.nz the anecdotal stage (Wyss et al., 1999). In Greece, a relation similar to that found by Rikitake (1979) was obtained by Papadopoulos (1988a) for precursory «bursts» of seismicity before several major earthquakes. Such «bursts» are different from the precursory swarms in the present study, and include events classed here as mainshock events.

The distinction between swarms and mainshock events was elucidated by Mogi (1963), who showed, by a series of laboratory experiments, that mainshock/aftershock events occur when the medium and stress-field are uniform, and swarms when they are non-uniform. The swarm as precursor to larger earthquakes was modelled by Kanamori (1981) in terms of fault asperities. These results were combined by $\mathrm{Mi}-$ kumo and Miyatake (1983), who studied in detail, by means of numerical simulations, the type of distribution of static and dynamic properties that would produce swarms followed by large earthquakes. In a further advance, Yama- 
shita and Knopoff (1992) postulated that earthquakes occur by the fracture of pre-existing cracks, and that swarms and mainshock events involve a power-law distribution of parallel cracks. On this model they obtained results which suggested some causal relation between swarms and mainshock events.

Systematic studies of the New Zealand and Japan earthquake catalogues have suggested that the precursory swarm phenomenon is an integral part of the seismogenic process for shallow earthquakes in subduction zones (Evison and Rhoades, 1998). Such studies depend on the availability of sufficiently lengthy and homogeneous earthquake catalogues. The catalogue of the Geophysical Laboratory, Aristotle University of Thessaloniki (AUTH) has the necessary qualities to support a similar systematic study in the Hellenic subduction zone in Greece. As required by formal hypothesis testing, this catalogue will be used throughout the present study.

\section{The precursory swarm hypothesis}

The hypothesis is that swarm events are longterm precursors to mainshock events, so that mainshock events can be forecast at long range by means of the related swarms. According to the empirical evidence, precursory swarms are a feature of shallow seismicity in subduction zones; this is therefore the environment to which the hypothesis applies. A given precursory sequence consists of one or more swarms followed by one or more mainshock events.

For the hypothesis to be testable, specifications are needed for the recognition of swarms and mainshock events. These features of the hypothesis have been found similar for Greece as for New Zealand and Japan, except that in each region some numerical quantities need to be adjusted to allow for local conditions. The limits of surveillance in any region under investigation also need to be specified. All specifications remain unchanged for the duration of a test.

The following recognition and surveillance details have been found appropriate, on empirical grounds, for applying the hypothesis to the region of Greece. Magnitude is a crucial param- eter. In the AUTH catalogue all magnitudes are given in a scale equivalent to the moment magnitude. The lower threshold of magnitude completeness is given as 4.0 from 1981 onwards, 4.3 from 1964, 4.5 from 1950 and 5.0 from 1911. Smaller swarms and mainshock events have thus been recognizable in more recent years.

\subsection{Event recognition}

Mainshock events and swarms are recognised as members of the class of multiple events. This class also includes multiplets, which are not precursory. The criteria for recognising and distinguishing between these events in the AUTH catalogue are:

i) Number $n$ of earthquakes in a multiple event:

$$
n \geq 4
$$

including at least 3 in 1.0 day.

ii) Magnitude distribution:

$$
\begin{array}{ll}
\text { Mainshock events } & M_{1}-M_{3} \geq 0.8 \\
\text { Swarms, multiplets } & M_{1}-M_{3} \leq 0.7
\end{array}
$$

where $M_{1}$ is the largest magnitude in the event, and $M_{3}$ is the third largest.

iii) Area $A$ :

$$
\begin{array}{ll}
\text { Swarms } & A \geq A\left(M_{p}\right) \\
\text { Multiplets } & A<A\left(M_{p}\right)
\end{array}
$$

where $A\left(\mathrm{~km}^{2}\right)$ is the area of the convex polygon circumscribing the epicentres, $M_{p}$ is the average of the three largest magnitudes in the event, and $A\left(M_{p}\right)$ is given by

$$
\log _{10} A\left(M_{p}\right)=0.42+0.50 M_{p} .
$$

iv) Duration: an event extends backward and forward in time until a vacant period of at least 50 days is reached.

Except for magnitude distribution, these criteria are the same as those used in the New Zealand study (Evison and Rhoades, 1993). 


\subsection{Limits of surveillance}

i) Location: the area of surveillance is the Hellenic arc as outlined in fig. 1. The outline is based on the relevant «seismogenic sources of shallow earthquakes» (Papazachos and Papazachou, 1997, fig. 7.1 and table 7.1).

ii) Depth:

$$
h \leq 60 \mathrm{~km} .
$$

iii) Magnitude:

$\begin{array}{ll}\text { All earthquakes } & M \geq 4.0 \\ \text { Mainshocks } & M_{m} \geq 6.2 \\ \text { Swarms } & M_{n} \geq 4.5\end{array}$

where $M_{m}$ is the mainshock magnitude, and $M_{p}$ is the average of the three largest magnitudes in a swarm or cluster of swarms.

iv) Time: the earliest multiple event recognised in the catalogue, according to the above rules, is the 1912 Kefallonia mainshock event $\left(M_{m} 6.8\right)$. The catalogue search extends up to the latest available date (5 May, 2000).

The multiple events that have been recognised are listed in table I (mainshock events), table II (swarms) and table III (multiplets). The multiplets, once identified, play no further part in the hypothesis.

The third-largest magnitude in an event $\left(M_{3}\right)$ is used in Section 2.1 (ii) above, and in the definition of the swarm magnitude $\left(M_{p}\right)$, so as to make the relevant parameters more statistically

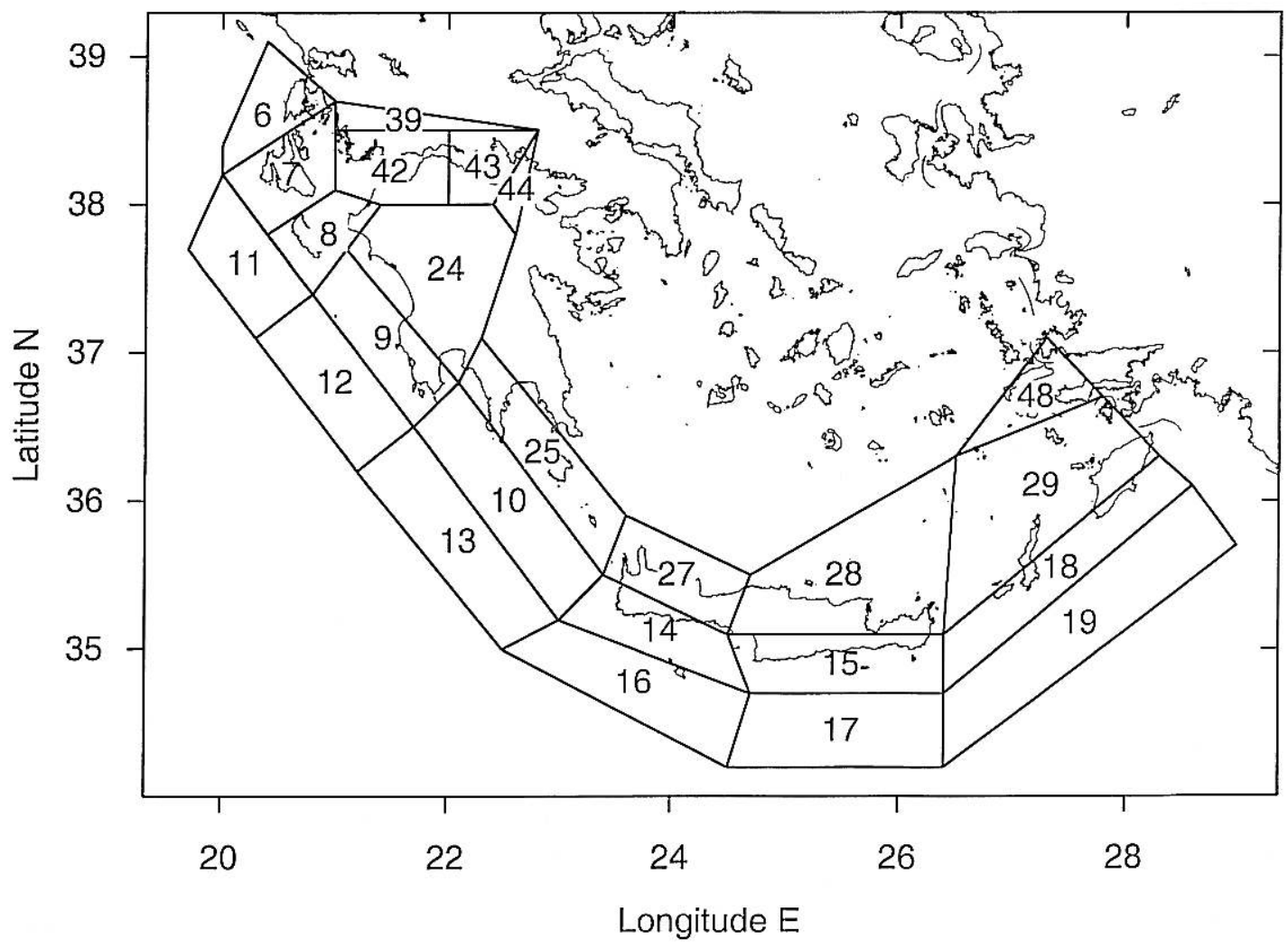

Fig. 1. Area of surveillance, showing seismogenic sources (after Papazachos and Papazachou, 1997). 
Table I. Mainshock events.

\begin{tabular}{|c|c|c|c|c|c|c|c|c|c|}
\hline $\mathrm{ME}$ & Time (UT) & Latit & tude $\mathrm{N}$ & Long & itude E & $n$ & $M_{1}-M_{3}$ & $M_{1}$ & Locality \\
\hline 1 & $1912.01 .24-1912.04 .21$ & 38.1 & -38.2 & 20.5 & -20.8 & 16 & 1.3 & 6.8 & Kefallonia \\
\hline 2 & $1948.02 .09-1948.03 .29$ & 35.5 & -35.5 & 27.2 & -27.2 & 10 & 1.6 & 7.1 & Karpathos \\
\hline 3 & $1953.06 .01-1954.03 .09$ & 37.5 & -38.6 & 20.3 & -21.4 & 113 & 0.8 & 7.2 & Kefallonia \\
\hline 4 & $1958.08 .27-1958.10 .10$ & 37.3 & -37.5 & 20.5 & -21.0 & 6 & 1.3 & 6.4 & Zakinthos \\
\hline 5 & 1959.05.14-1959.06.05 & 35.0 & -35.25 & 24.6 & -24.8 & 6 & 2.0 & 6.3 & Crete \\
\hline 6 & $1959.11 .15-1959.12 .01$ & 37.7 & -37.8 & 20.1 & -20.53 & 8 & 1.4 & 6.8 & Kefallonia \\
\hline 7 & $1962.04 .10-1962.04 .19$ & 37.5 & -37.9 & 20.1 & -20.2 & 30 & 1.0 & 6.3 & Kefallonia \\
\hline 8 & $1972.08 .14-1973.03 .25$ & 38.03 & -38.38 & 20.03 & -20.48 & 83 & 1.5 & 6.3 & Kefallonia \\
\hline 9 & $1976.05 .11-1976.07 .14$ & 37.03 & -37.65 & 20.19 & -20.97 & 28 & 1.1 & 6.5 & Ionian Sea \\
\hline 10 & $1977.06 .10-1978.03 .10$ & 34.65 & -35.36 & 22.80 & -23.72 & 42 & 1.1 & 6.3 & SW off Crete \\
\hline 11 & $1983.01 .17-1984.06 .28$ & 37.768 & $3-38.592$ & 19.84 & $3-20.852$ & 541 & 1.2 & 7.0 & Kefallonia \\
\hline 12 & 1984.06.16-1984.08.02 & 34.750 & )-35.400 & 22.698 & -23.300 & 18 & 1.4 & 6.2 & SW off Crete \\
\hline 13 & $1995.06 .15-1995.08 .06$ & 38.268 & $3-38.541$ & 22.01 & $3-22.322$ & 19 & 1.5 & 6.4 & Aeghio \\
\hline 14 & 1996.07.20-1997.09.11 & 35.900 & $0-36.486$ & 27.03 & $2-27.643$ & 378 & 1.1 & 6.2 & W off Rodhos \\
\hline 15 & $1997.09 .02-1999.12 .30$ & 36.962 & $2-37.650$ & 20.45 & $0-21.256$ & 284 & 1.2 & 6.6 & Zakinthos \\
\hline 16 & $1997.10 .13-1997.11 .02$ & 36.287 & $7-36.486$ & $21.81 \mathrm{C}$ & $0-22.311$ & 9 & 1.7 & 6.4 & Kithira \\
\hline
\end{tabular}

$M_{1}-M_{i} \geq 0.8 ; M_{1} \geq 6.2$.

Complete to 2000.06.05.

robust, considering that individual magnitude estimates are subject to appreciable error. Citing these parameters, and the above magnitude thresholds, to the first decimal point does not imply a level of precision. Rigorous hypothesis testing requires definite quantitative rules, and if the chosen rules do not fit all cases the hypothesis will perform less well, but will nevertheless survive if sufficiently robust.

\section{Historical precursory sequences and score-sheet}

Two further steps are required to complete the formulation of the hypothesis: identifying the historical sequences of precursory swarms and related mainshock events, and the associated step of compiling a score-sheet of past events. These matters are properly regarded as an integral part of the hypothesis, and not as a verification of it or a test of its significance. The se- quences provide quantitative data for the correlation of swarms and mainshock events with respect to location, magnitude and time, and hence for estimating the hazard due to future mainshock events. On the other hand, from a Bayesian analysis of the score-sheet one estimates the expected rates of occurrence of unrelated swarms and mainshocks, which are also part of the hazard.

Of the 16 mainshock events recognised according to the above criteria (table I), 12 are found to have been preceded by swarms that occurred in the same localities, and were related to the mainshocks as regards magnitude and time. These events make up the historical precursory sequences for Greece, as listed in table IV, where the mainshock events and related swarms are identified by the serial numbers given in tables I and II. In table IV the date for a swarm (S), or cluster of swarms, is the magnitude-weighted mean date of all the swarm earthquakes, while the date for a mainshock event (ME) is the date of the mainshock itself. $T_{p}$ is the 
Table II. Swarms.

\begin{tabular}{|c|c|c|c|c|c|c|c|c|c|c|}
\hline$S$ & Time (UT) & Latit & tude $\mathrm{N}$ & Long & itude E & $n$ & $M_{1}-M_{3}$ & $M_{n}$ & $A\left(\mathrm{~km}^{2}\right)$ & Locality \\
\hline 1 & $1914.11 .23-1915.10 .07$ & 37.7 & -39.2 & 20.3 & -21.33 & 30 & 0.3 & 6.6 & 11860 & Kefallonia \\
\hline 2 & $1932.05 .14-1932.07 .03$ & 35.0 & -35.9 & 27.5 & -28.5 & 5 & 0.3 & 5.4 & 2045 & Karpathos \\
\hline 3 & 1951.01.08-1951.04.05 & 37.7 & -38.8 & 20.3 & -21.1 & 9 & 0.4 & 5.1 & 3578 & Kefallonia \\
\hline 4 & $1952.08 .24-1952.10 .12$ & 37.2 & -37.5 & 20.6 & -21.6 & 12 & 0.7 & 5.4 & 2228 & Zakinthos \\
\hline 5 & $1967.07 .05-1967.07 .14$ & 36.4 & -36.8 & 20.8 & -21.5 & 8 & 0.4 & 4.7 & 1436 & Ionian Sea \\
\hline 6 & 1969.03.08-1969.07.12 & 37.7 & -38.3 & 19.7 & -20.7 & 32 & 0.4 & 4.8 & 4416 & Kefallonia \\
\hline 7 & $1970.06 .30-1970.11 .03$ & 37.90 & -38.90 & 19.80 & -20.84 & 44 & 0.1 & 5.0 & 6619 & Kefallonia \\
\hline 8 & $1974.01 .24-1974.03 .13$ & 37.06 & -37.36 & 20.56 & -21.14 & 16 & 0.0 & 4.5 & 1216 & Ionian Sea \\
\hline 9 & $1974.03 .08-1974.04 .28$ & 34.44 & -34.85 & 24.57 & -24.85 & 10 & 0.3 & 4.8 & 755 & $S$ off Crete \\
\hline 10 & $1974.08 .21-1974.11 .23$ & 37.63 & -38.08 & 19.83 & -20.65 & 17 & 0.3 & 4.7 & 2227 & Kefallonia \\
\hline 11 & $1976.11 .25-1976.11 .28$ & 36.35 & -36.80 & 26.99 & -27.44 & 9 & 0.2 & 4.7 & 1072 & Nisiros \\
\hline 12 & $1981.04 .10-1982.12 .10$ & 37.707 & $7-38.940$ & 19.9 & $3-21.070$ & 308 & 0.4 & 5.4 & 10593 & Kefallonia \\
\hline 13 & 1983.12.14-1984.02.24 & 37.2 & $7-37.589$ & 20.7 & 21.017 & 15 & 0.1 & 4.5 & 616 & Ionian Sea \\
\hline 14 & 1987.04.03-1987.06.28 & & $0-36.210$ & 27.030 & $0-27.570$ & 21 & 0.1 & 5.0 & 2569 & W off Rodhos \\
\hline 15 & $1988.04 .05-1988.08 .31$ & 37.860 & $0-38.580$ & 20.090 & $0-20.620$ & 72 & 0.4 & 5.2 & 2333 & Kefallonia \\
\hline 16 & $1988.08 .22-1990.12 .05$ & 37.180 & $0-38.030$ & 20.520 & $0-21.320$ & 164 & 0.7 & 5.7 & 5283 & Zakinthos \\
\hline 17 & $1989.04 .12-1989.08 .31$ & 37.950 & $0-38.390$ & 21.6 & $0-22.690$ & 11 & 0.4 & 4.9 & 2558 & Aeghio \\
\hline 18 & $1989.12 .26-1990.10 .14$ & 35.920 & $0-36.470$ & 27.0 & & 153 & 0.4 & 5.3 & 1840 & W off Rodhos \\
\hline 19 & $1993.02 .10-1993.08 .11$ & 37.500 & $0-37.970$ & 20.860 & -21.660 & 44 & 0.5 & 5.1 & & Amalias \\
\hline 20 & $1993.12 .23-1994.02 .28$ & 35.828 & $8-36.552$ & 21.559 & $9-22.190$ & 11 & 0.4 & 5.3 & 2175 & Kithira \\
\hline 21 & $1994.11 .29-1995.03 .16$ & 38.46 & $7-38.997$ & 20.276 & $6-20.652$ & 26 & 0.6 & 5.0 & 1216 & Levkas \\
\hline 22 & $1998.01 .19-1998.06 .13$ & 36.470 & $0-36.800$ & 26.940 & $0-27.660$ & 37 & 0.2 & 4.5 & 1626 & W off Rodhos \\
\hline 23 & $1998.03 .03-1999.01 .04$ & 34.808 & $8-35.340$ & 25.500 & $0-26.073$ & 31 & 0.2 & 4.6 & 2161 & E Crete \\
\hline 24 & $1998.08 .13-1998.11 .13$ & 35.950 & $0-36.320$ & 26.870 & $0-27.220$ & 12 & 0.5 & 4.6 & 751 & W off Rodhos \\
\hline 25 & 1998.09.01-1999.01.24 & 37.740 & $0-38.135$ & 20.181 & $1-20.650$ & 21 & 0.6 & 4.8 & 1141 & Kefallonia \\
\hline 26 & $1998.12 .23-1999.05 .11$ & 34.350 & $0-34.940$ & 25.180 & $0-25.630$ & 22 & 0.2 & 4.9 & 1530 & $S$ of E Crete \\
\hline 27 & $1999.04 .17-1999.06 .12$ & 35.570 & $0-36.040$ & 21.250 & $0-21.720$ & 14 & 0.6 & 5.0 & 1153 & Ionian Sea \\
\hline 28 & $2000.03 .31-2000.05 .24$ & 34.130 & $0-34.860$ & 25.450 & $0-25.900$ & 20 & 0.3 & 4.9 & 2452 & $S$ of E Crete \\
\hline
\end{tabular}

$M_{1}-M_{3} \leq 0.7 ; M_{p} \geq 4.5$.

Complete to 2000.06.05.

time in days between the swarm and mainshock dates.

The catalogue data on the eight later sequences, $\mathrm{Gc}-\mathrm{Gj}$, are sufficient to show in fine detail the four-dimensional relation between swarms and mainshock events. The data are presented in figs. 2.1-2.8. The epicentre plots show the relative locations of precursory swarms, mainshocks and aftershocks. For definiteness, the hypothesis is concerned with estimating the locations of mainshocks, not aftershocks. (The mainshock epicentre in fig. 2.4 is obscured by other epicentres; it is at N38.10, E20.20.) The degree of correspondence for all the sequences identified in Japan, New Zealand and Greece will be discussed below (Section 4).

The sequence of swarm and mainshock event as an anomaly with respect to magnitude and 
Table III. Multiplets.

\begin{tabular}{|c|c|c|c|c|c|c|c|c|c|c|}
\hline \multirow{2}{*}{$\frac{\mathrm{Mu}}{1}$} & \multirow{2}{*}{$\frac{\text { Time (UT) }}{1927.03 .24-1927.03 .29}$} & \multicolumn{2}{|c|}{ Latitude $\mathrm{N}$} & \multicolumn{2}{|c|}{ Longitude $\mathrm{E}$} & \multirow{2}{*}{$\frac{n}{4}$} & \multirow{2}{*}{$\frac{M_{1}-M_{3}}{0.5}$} & \multirow{2}{*}{$\frac{M_{p}}{5.3}$} & \multirow{2}{*}{$\frac{A\left(\mathrm{~km}^{2}\right)}{0}$} & \multirow{2}{*}{$\begin{array}{c}\text { Locality } \\
\text { S off Crete }\end{array}$} \\
\hline & & 35.0 & -35.0 & 26.0 & -26.0 & & & & & \\
\hline 2 & $1952.12 .22-1953.01 .01$ & 35.5 & -35.7 & 25.3 & -25.8 & 5 & 0.5 & 5.4 & 502 & Off NE Crete \\
\hline 3 & 1956.07.30-1956.10.29 & 35.5 & -36.0 & 25.9 & -26.1 & 12 & 0.5 & 5.7 & 851 & Lasithi \\
\hline 4 & $1961.02 .23-1961.03 .13$ & 36.5 & -36.7 & 26.9 & -27.4 & 7 & 0.5 & 5.3 & 495 & Nisiros \\
\hline 5 & 1966.05.24-1966.07.09 & 37.2 & -37.43 & 21.7 & -22.0 & 9 & 0.7 & 4.9 & 437 & Messini \\
\hline 6 & $1968.09 .15-1968.09 .18$ & 34.6 & -34.9 & 24.7 & -25.0 & 7 & 0.4 & 4.8 & 617 & S off Crete \\
\hline 7 & $1969.03 .26-1969.05 .15$ & 35.0 & -35.4 & 27.7 & -28.0 & 17 & 0.2 & 5.4 & 913 & S off Rodhos \\
\hline 8 & $1970.02 .18-1970.04 .04$ & 36.30 & -36.70 & 27.00 & -27.27 & 7 & 0.0 & 4.5 & 425 & Nisiros \\
\hline 9 & $1971.03 .24-1971.03 .25$ & 37.92 & -38.07 & 20.06 & -20.31 & 4 & 0.5 & 4.5 & 170 & Kefallonia \\
\hline 10 & $1973.11 .12-1974.01 .17$ & 35.20 & -35.80 & 27.57 & -27.86 & 11 & 0.3 & 5.2 & 815 & S off Rodhos \\
\hline 11 & 1975.06.23-1976.01.20 & 38.27 & -38.56 & 21.49 & -22.00 & 47 & 0.2 & 5.6 & 990 & G. Corinth \\
\hline 12 & 1979.03.06-1979.04.09 & 37.43 & -37.70 & 21.33 & -21.55 & 10 & 0.4 & 4.7 & 300 & Pirgos \\
\hline 13 & $1981.02 .10-1981.02 .11$ & 34.23 & $2-34.356$ & 23.598 & $8-23.678$ & 4 & 0.0 & 4.8 & 53 & S off Crete \\
\hline 14 & $1981.08 .17-1981.10 .09$ & $34.63 ?$ & $2-34.875$ & 25.019 & $9-25.1$ & 12 & 0.4 & 5.0 & 248 & $S$ off Crete \\
\hline 15 & $1982.04 .26-1982.05 .05$ & 37.6 & $0-37.810$ & 21.3 & -21.560 & 15 & 0.3 & 4.7 & 167 & Pirgos \\
\hline 16 & $1982.09 .20-1982.09 .21$ & 34.09 & $0-34.580$ & 26.030 & -26.330 & 6 & 0.3 & 5.2 & 689 & SE off Crete \\
\hline 17 & $1983.11 .20-1983.11 .26$ & 36.20 & $0-36.459$ & 26.904 & $4-27.083$ & 6 & 0.1 & 4.6 & 218 & W off Rodhos \\
\hline 18 & $1984.10 .09-1985.01 .08$ & 37. & $0-37.182$ & 21.670 & -21.788 & 9 & 0.6 & 4.9 & 82 & Kalamata \\
\hline 19 & $1985.05 .10-1985.05 .13$ & 35.52 & $0-35.598$ & 27.159 & $9-27.298$ & 4 & 0.0 & 4.7 & 53 & Karpathos \\
\hline 20 & 1987.01.01-1987.02.24 & 36.21 & $0-36.310$ & 27.970 & -28.130 & 9 & 0.1 & 4.8 & 47 & Rodhos \\
\hline 21 & $1987.10 .05-1987.10 .27$ & 36.19 & $0-36.350$ & 28.130 & $0-28.310$ & 13 & 0.2 & 5.2 & 174 & Rodhos \\
\hline 22 & $1989.08 .24-1989.08 .31$ & 37.84 & $0-38.080$ & 20.070 & $0-20.160$ & 6 & 0.6 & 4.8 & 114 & Kefallonia \\
\hline 23 & $1990.11 .14-1990.11 .30$ & 35.34 & $0-35.640$ & 26.660 & $0-26.800$ & 5 & 0.2 & 4.6 & 73 & NE off Crete \\
\hline 24 & $1992.10 .25-1992.12 .20$ & 37.22 & $0-37.400$ & 21.530 & $0-21.740$ & 8 & 0.5 & 4.5 & 120 & Messini \\
\hline 25 & 1995.02.03-1995.05.04 & 36.02 & $8-36.234$ & 27.406 & $6-27.728$ & 11 & 0.2 & 4.6 & 338 & W off Rodhos \\
\hline 26 & $1996.03 .23-1996.11 .09$ & 35.25 & $9-35.477$ & 26.870 & $0-27.195$ & 41 & 0.1 & 4.7 & 490 & E off Crete \\
\hline 27 & $1996.10 .08-1996.10 .24$ & 36.79 & $0-36.973$ & 21.358 & $8-21.578$ & 20 & 0.1 & 4.9 & 227 & Ionian Sea \\
\hline 28 & $1997.04 .28-1997.05 .03$ & 37.41 & $6-37.637$ & 20.612 & $2-20.993$ & 6 & 0.5 & 4.5 & 305 & Zakinthos \\
\hline 29 & $2000.04 .27-2000.05 .03$ & 38.31 & $0-38.386$ & 22.070 & $0-22.148$ & 6 & 0.7 & 4.5 & 28 & Aeghio \\
\hline
\end{tabular}

$M_{1}-M_{3} \leq 0.7 ; M_{n} \geq 4.5$.

Complete to 2000.06.05.

time is shown on the right-hand side of figs. 2.12.8. Here the plots include not only the swarms and mainshock events, but all earthquakes (above magnitude threshold) that were located within the relevant rectangle during a period beginning much earlier than the swarms. The upper plot shows the time and magnitude of each earthquake larger than the chosen magnitude. The lower plot presents the same data in the form of a cumulative magnitude anomaly (cumag), $C(t)$, which is a type of cusum designed to show up temporal changes in the level of seismicity, having regard for magnitude. $C(t)$ is defined by

$$
\begin{gathered}
C(t)=\sum_{t s \leq t i \leq t}\left(M_{i}-M_{c}+0.1\right)-k\left(t-t_{s}\right) \\
k=\Sigma_{t s \leq t i \leq t f}\left(M_{i}-M_{c}+0.1\right) /\left(t_{f}-t_{s}\right)
\end{gathered}
$$


Table IV. Historical sequences of swarms (S) and related mainshock events (ME).

\begin{tabular}{|c|c|c|c|c|c|c|}
\hline Sequence & Locality & Events & Date & $M_{p}$ & $M_{m}$ & $T_{p}$ (days) \\
\hline \multirow[t]{4}{*}{$\mathrm{Ga}$} & Kefallonia & $\mathrm{S} 1,3$ & 1922.11 .18 & 6.6 & & \\
\hline & & ME 3 & 1953.08 .12 & & 7.2 & 11225 \\
\hline & & ME 6 & 1959.11 .15 & & 6.8 & 13511 \\
\hline & & ME 7 & 1962.04 .10 & & 6.3 & 14388 \\
\hline \multirow[t]{2}{*}{$\mathrm{Gb}$} & Karpathos & S 2 & 1932.06 .22 & 5.4 & & \\
\hline & & ME 2 & 1948.02 .09 & & 7.1 & 5710 \\
\hline \multirow[t]{2}{*}{$\mathrm{Gc}$} & Zakinthos & S 4 & 1952.09 .27 & 5.4 & & \\
\hline & & ME 4 & 1958.08 .27 & & 6.4 & 2160 \\
\hline \multirow[t]{2}{*}{$\mathrm{Gd}$} & Kefallonia & S 6,7 & 1970.02 .09 & 5.0 & & \\
\hline & & ME 8 & 1972.09 .17 & & 6.3 & 951 \\
\hline \multirow[t]{2}{*}{$\mathrm{Ge}$} & Ionian Sea & S 8 & 1974.02 .21 & 4.5 & & \\
\hline & & ME 9 & 1976.05 .11 & & 6.5 & 810 \\
\hline \multirow[t]{2}{*}{ Gf } & Kefallonia & S 10,12 & 1981.04 .09 & 5.4 & & \\
\hline & & ME 11 & 1983.01 .17 & & 7.0 & 648 \\
\hline \multirow[t]{2}{*}{$\mathrm{Gg}$} & Zakinthos & S $13,16,19$ & 1989.11 .13 & 5.7 & & \\
\hline & & ME 15 & 1997.11 .18 & & 6.6 & 2927 \\
\hline \multirow[t]{2}{*}{ Gh } & W off Rodhos & S 14,18 & 1989.11 .11 & 5.3 & & \\
\hline & & ME 14 & 1996.07 .20 & & 6.2 & 2443 \\
\hline \multirow[t]{2}{*}{ Gi } & Aeghio & S 17 & 1989.05 .26 & 4.9 & & \\
\hline & & ME 13 & 1995.06 .15 & & 6.4 & 2211 \\
\hline \multirow[t]{2}{*}{$\mathrm{Gj}$} & Kithira & S 20 & 1994.01 .20 & 5.3 & & \\
\hline & & ME 16 & 1997.10 .13 & & 6.4 & 1362 \\
\hline
\end{tabular}

where $M_{i}$ is the magnitude and $t_{i}$ the time of the $i$ th earthquake, $M$ is the threshold magnitude, and $k$ is the average rate of magnitude accumulation between the starting time $t_{s}$ and the finishing time $t_{f}$. Accordingly, each earthquake is represented by an upward jump equal to the amount by which the magnitude exceeds the baseline value, which is 0.1 below the threshold magnitude. The downward slope between successive earthquakes is equal and opposite to the sum of all the upward jumps, divided by the total time. It follows that the gradient of the line between any two points on the $C(t)$ curve is a measure of the average rate of earthquake activity during the corresponding time period.

Swarms contribute to an increased average rate of earthquake activity in the period leading up to the mainshock, as can be seen in the $C(t)$ graphs in figs. 2.1-2.8. The onset of this increase is taken as the lowest point of the graph. Thus the increased (precursory) rate is given by the gradient of a straight line between the lowest point and the zero point immediately before the mainshock, while the earlier rate is obtained by joining the initial zero point to the lowest point. The onset date and the average rates of seismicity 

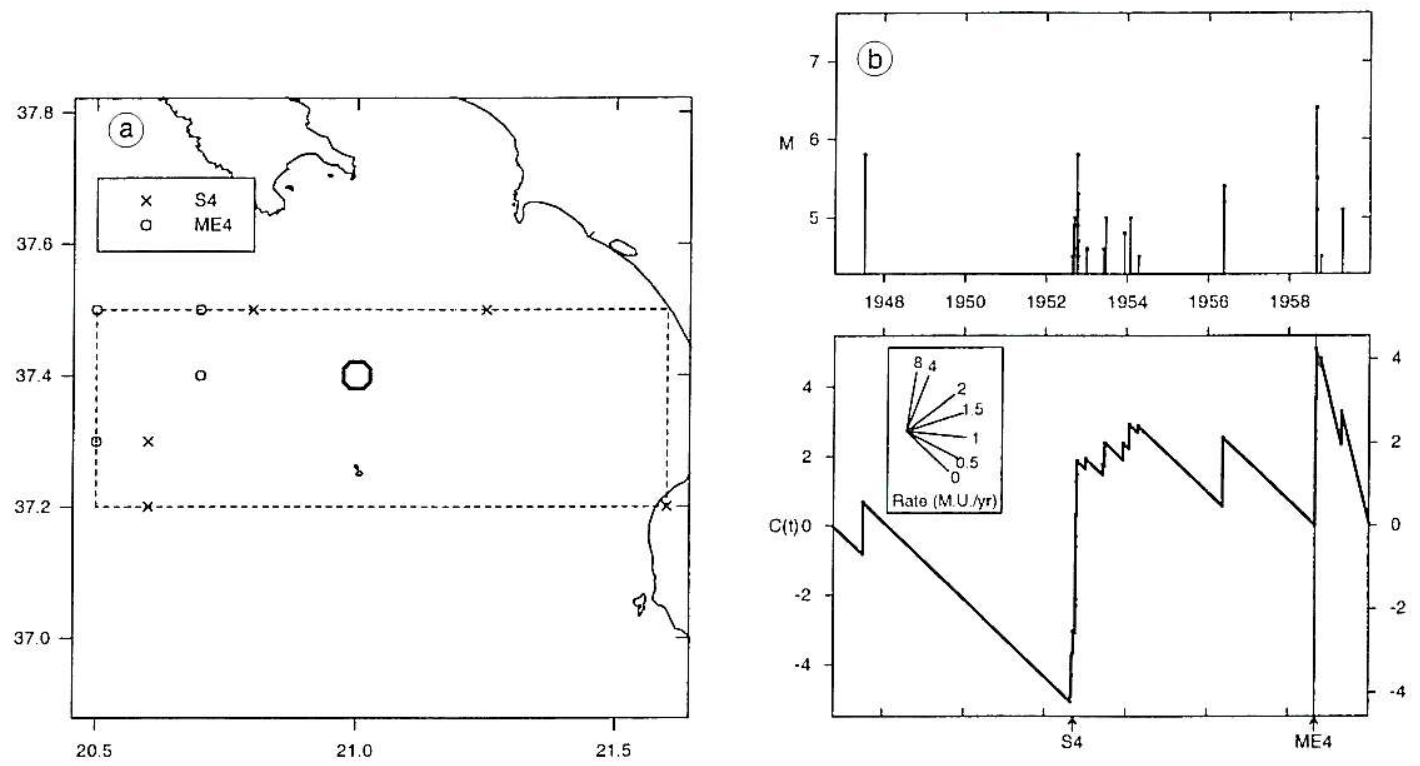

Fig. 2.1. Historical sequence Gc: Zakinthos (table 4), showing (a) epicentres, and (b) magnitudes versus time. Dashed-line frames indicate sequence limits. Mainshock events (ME) and swarms (S) are numbered as in table I and table II. In (a) the mainshocks are shown as large symbols. In (b) the upper graph shows the magnitude and time of each earthquake: the lower graph shows the cumulative magnitude anomaly $C(t)$, given by eq. (3.1). The scale of $C(t)$ is given on the left for the pre-mainshock period, and on the right for the mainshock-aftershock period. The gradient of the line between any two points on $C(t)$ is a measure of the average seismicity rate during the corresponding time interval. For the pre-mainshock period, this is indicated by a protractor. Rate is measured in Magnitude Units per year (MU/yr), where magnitude is reckoned from the baseline value. Rates are not comparable between sequences. Data on the rate change which marks the onset of mainshock seismogenesis are given in table $\mathrm{V}$.

Table V. Precursory increase in seismicity rate.

\begin{tabular}{lcccccc}
\hline \hline \multicolumn{1}{c}{ Location } & Sequence & Figure & Onset date & \multicolumn{2}{c}{ Seismicity rate (MU/yr) } & $\begin{array}{c}\text { Increase } \\
\text { ratio }\end{array}$ \\
\hline Zakinthos & $\mathrm{Gc}$ & $2.1 \mathrm{~b}$ & 1952.08 .26 & 0.26 & 1.97 & 7.58 \\
Kefallonia & $\mathrm{Gd}$ & $2.2 \mathrm{~b}$ & 1969.01 .05 & 6.28 & 20.22 & 3.22 \\
Ionian Sea & $\mathrm{Ge}$ & $2.3 \mathrm{~b}$ & 1972.07 .07 & 1.99 & 4.37 & 2.20 \\
Kefallonia & $\mathrm{Gf}$ & $2.4 \mathrm{~b}$ & 1981.05 .11 & 11.06 & 84.71 & 7.66 \\
Zakinthos & $\mathrm{Gg}$ & $2.5 \mathrm{~b}$ & 1981.06 .21 & 7.33 & 13.85 & 1.89 \\
W off Rodhos & $\mathrm{Gh}$ & $2.6 \mathrm{~b}$ & 1987.01 .01 & 3.77 & 13.71 & 3.64 \\
Aeghio & $\mathrm{Gi}$ & $2.7 \mathrm{~b}$ & 1988.12 .23 & 0.70 & 4.23 & 6.04 \\
Kithira & $\mathrm{Gj}$ & $2.8 \mathrm{~b}$ & 1993.10 .29 & 1.16 & 4.22 & 3.64 \\
\hline
\end{tabular}

Note: Seismicity rates are not comparable between different locations. 

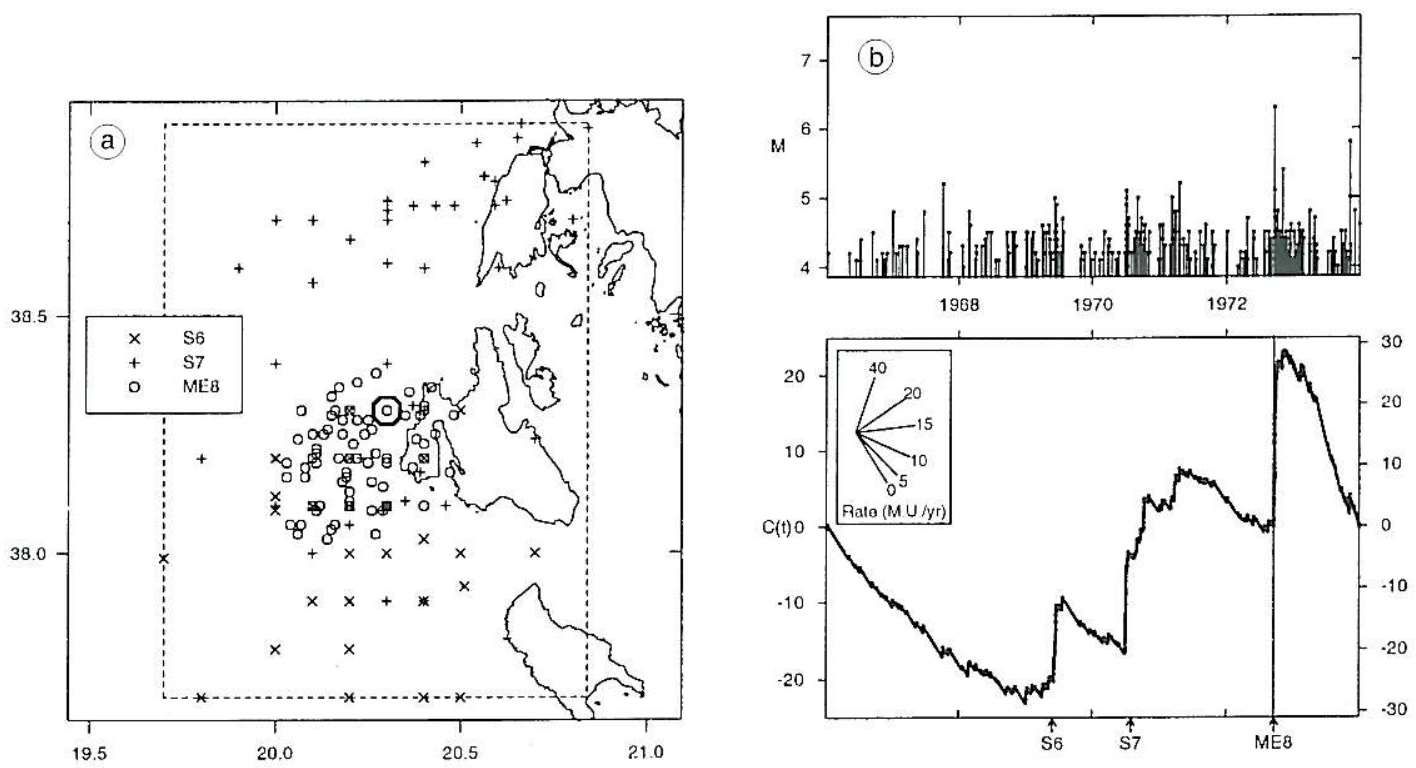

Fig. 2.2. Historical sequence Gd: Kefallonia. For explanation see caption fig. 2.1.
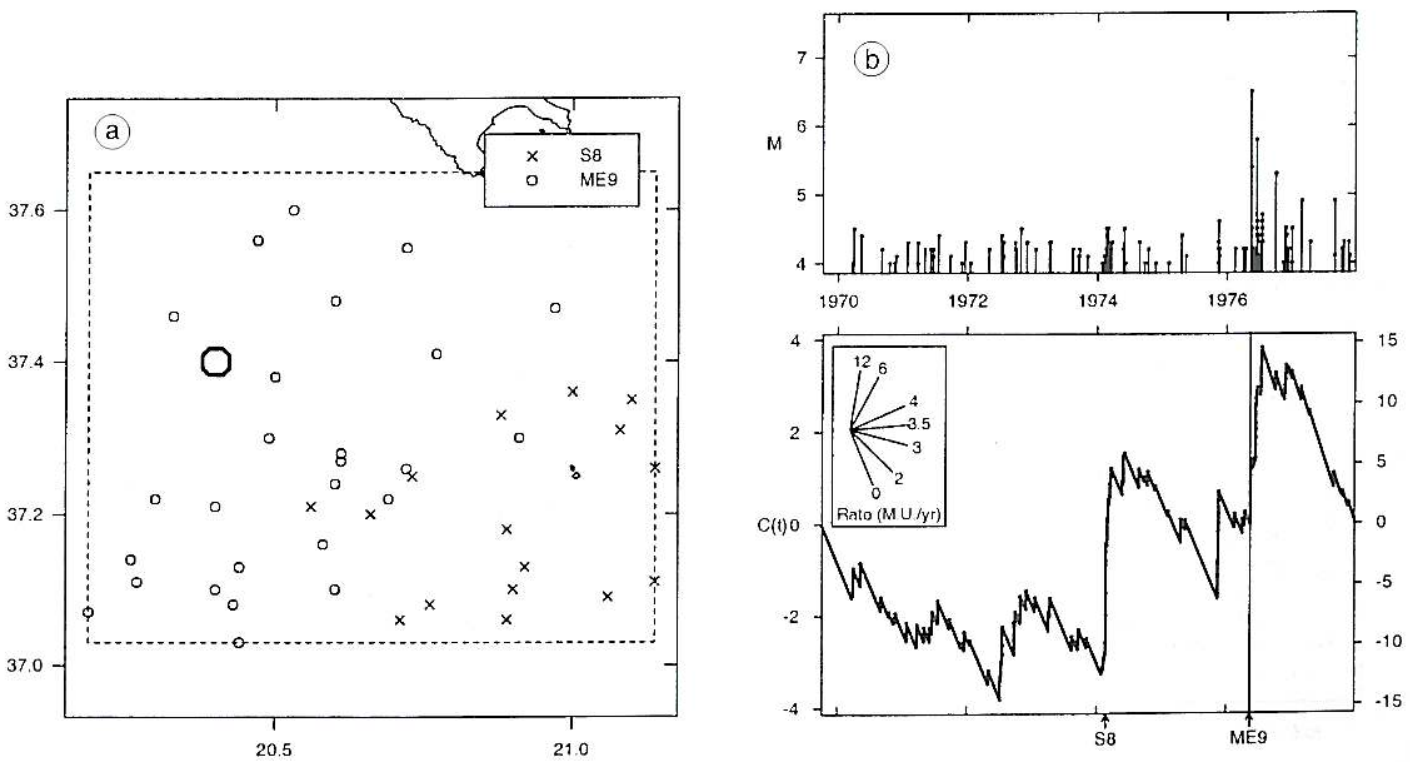

Fig. 2.3. Historical sequence Ge: Ionian Sea. For explanation see caption fig. 2.1. 

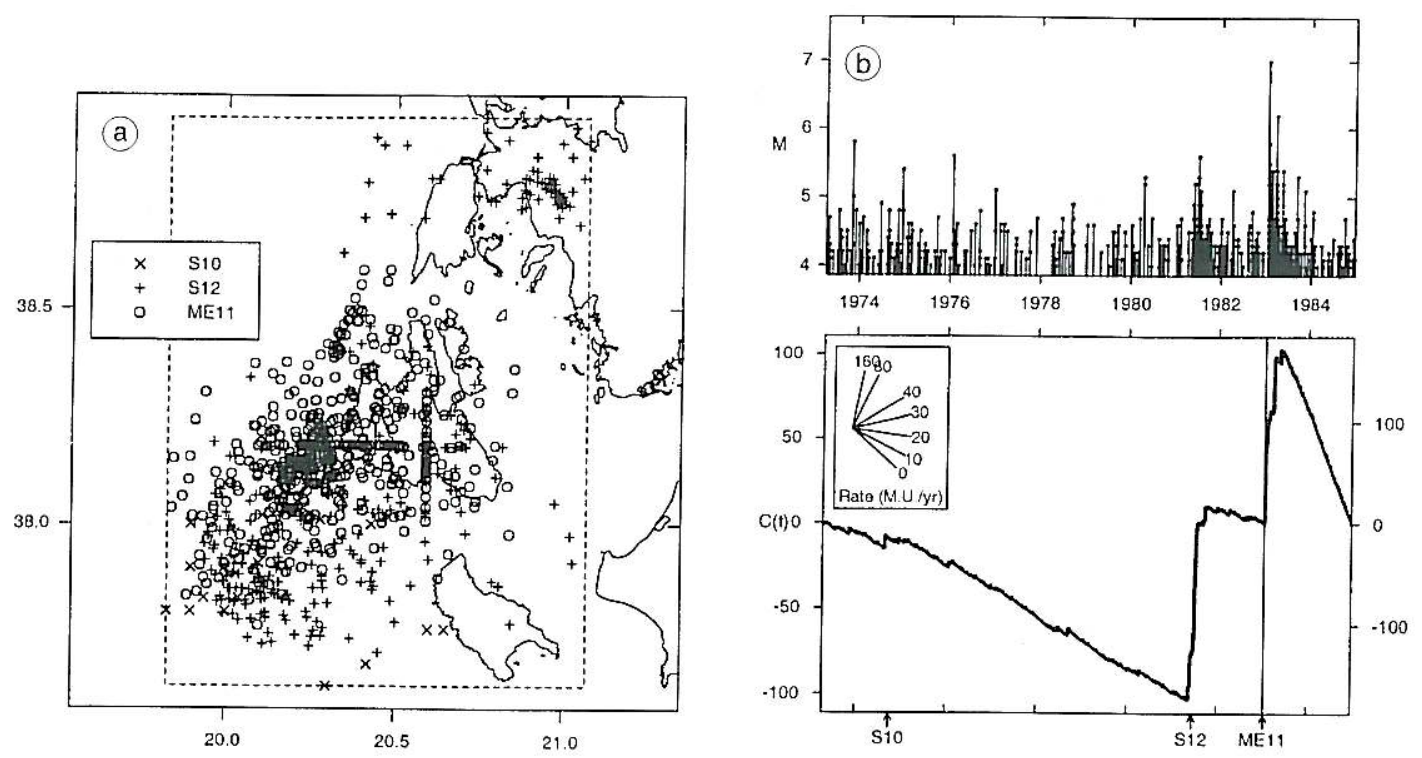

Fig. 2.4. Historical sequence Gf: Kefallonia. For explanation see caption fig. 2.1.
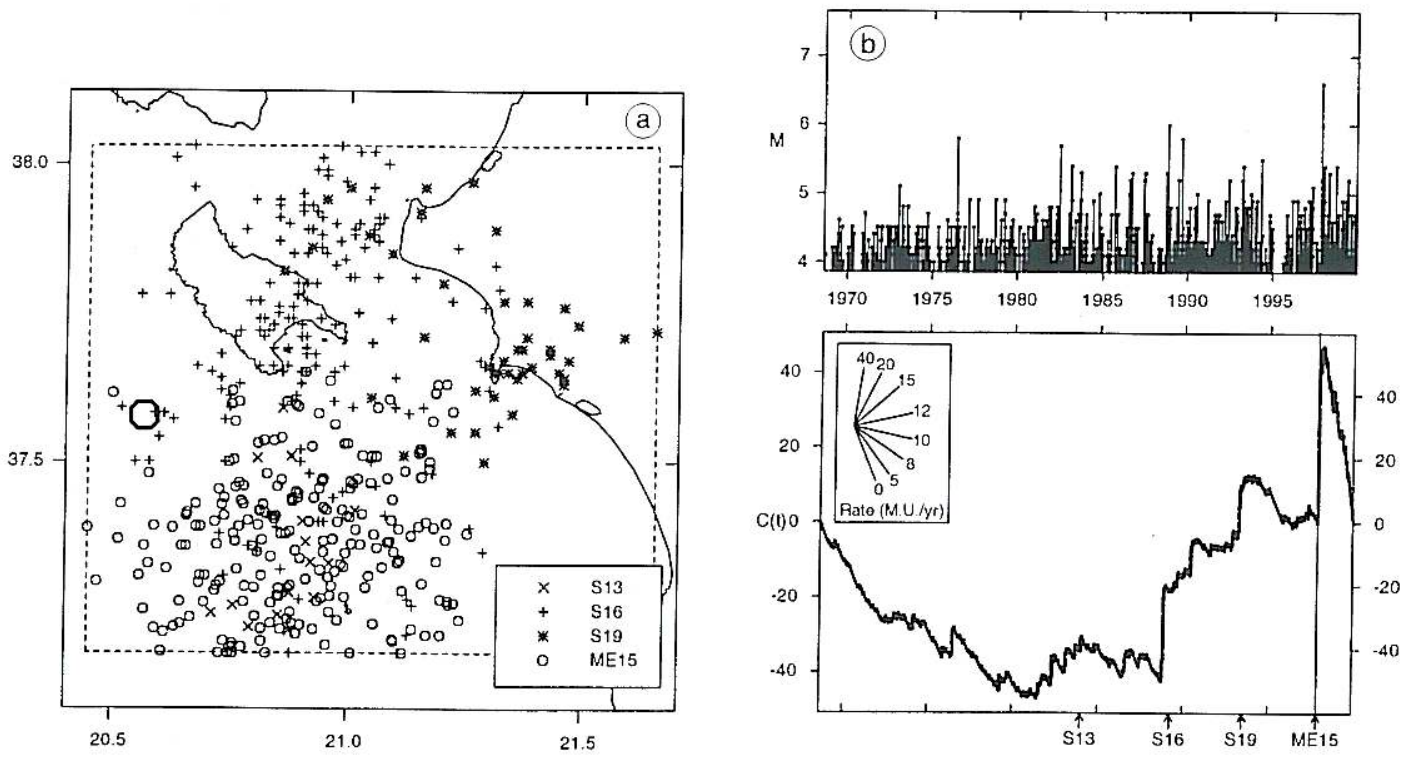

Fig. 2.5. Historical sequence Gg: Zakinthos. For explanation see caption fig. 2.1. 

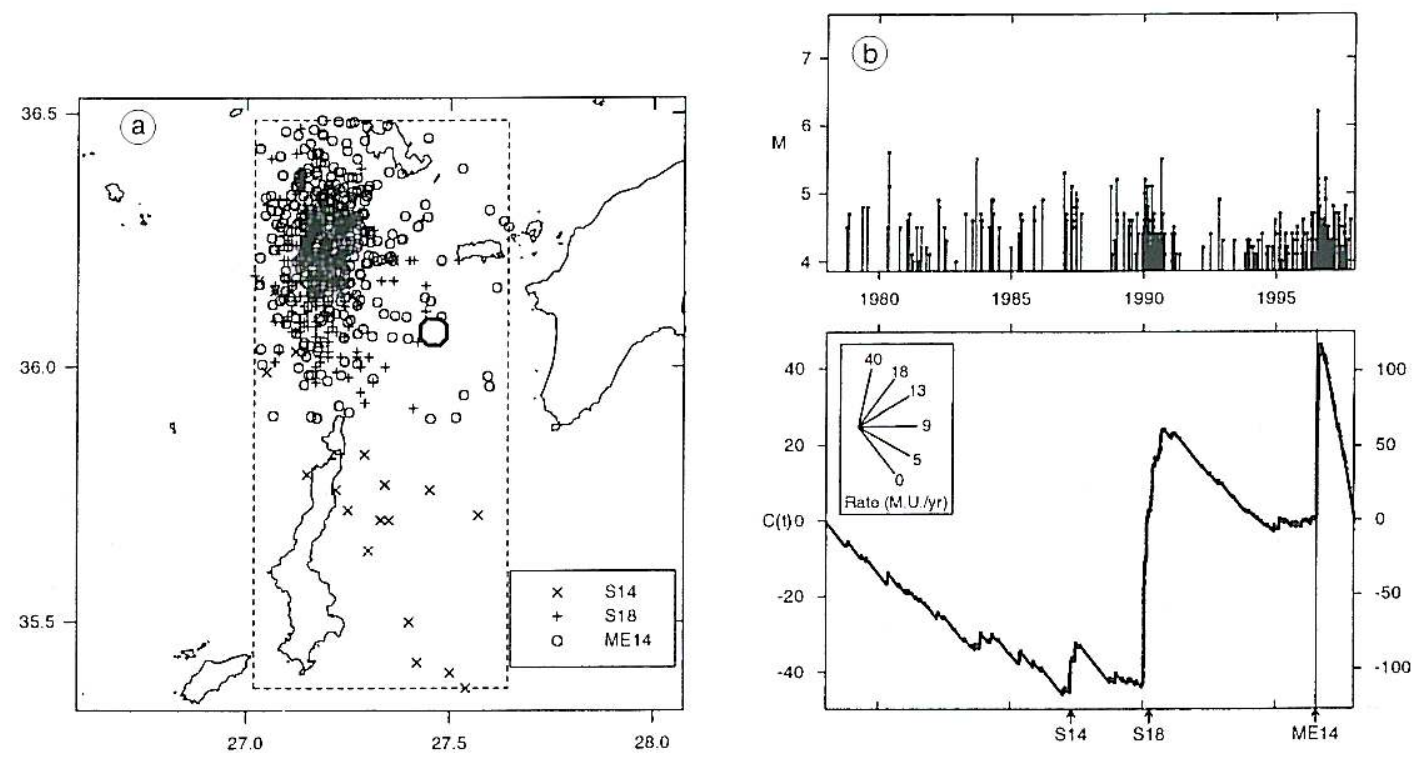

Fig. 2.6. Historical sequence Gh: W off Rodhos. For explanation see caption fig. 2.1.
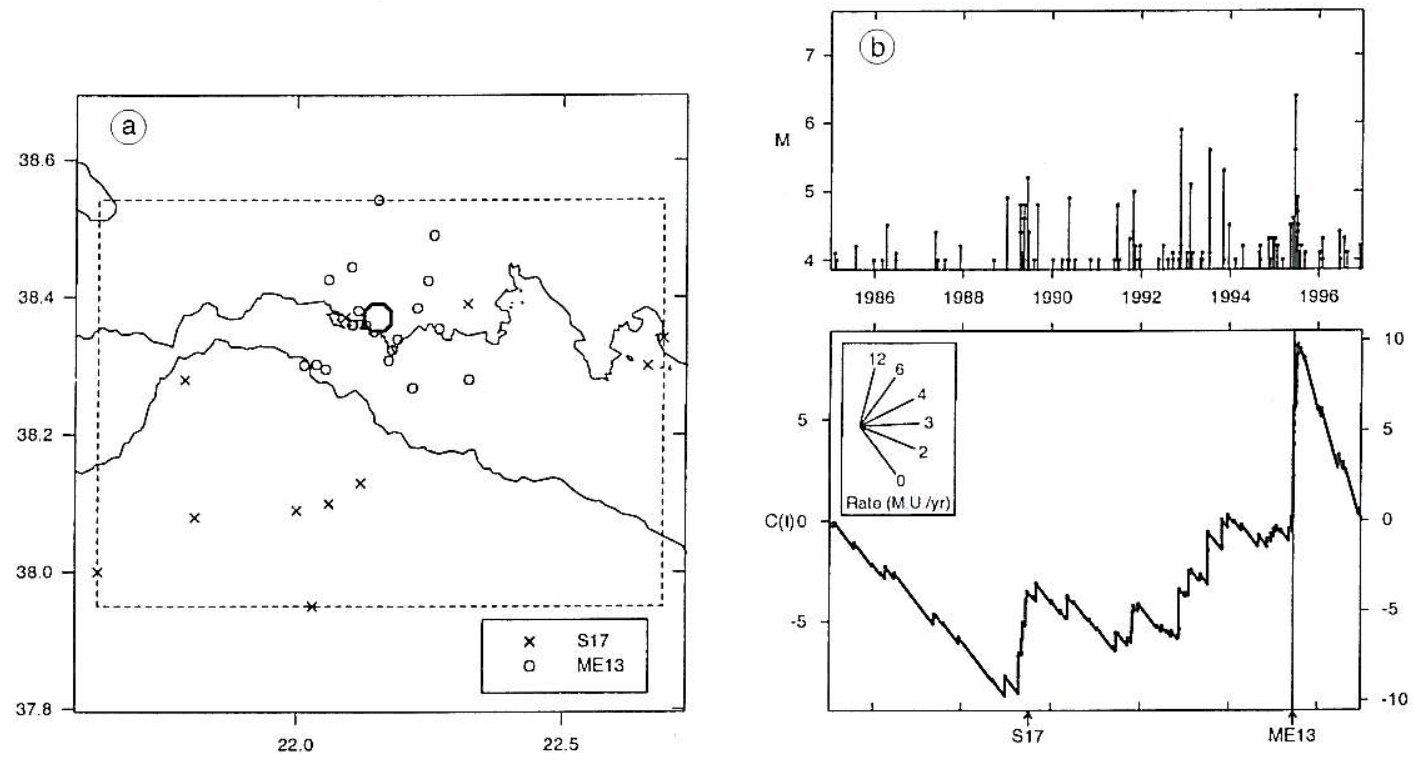

Fig. 2.7. Historical sequence Gi: Aeghio. For explanation see caption fig. 2.1. 

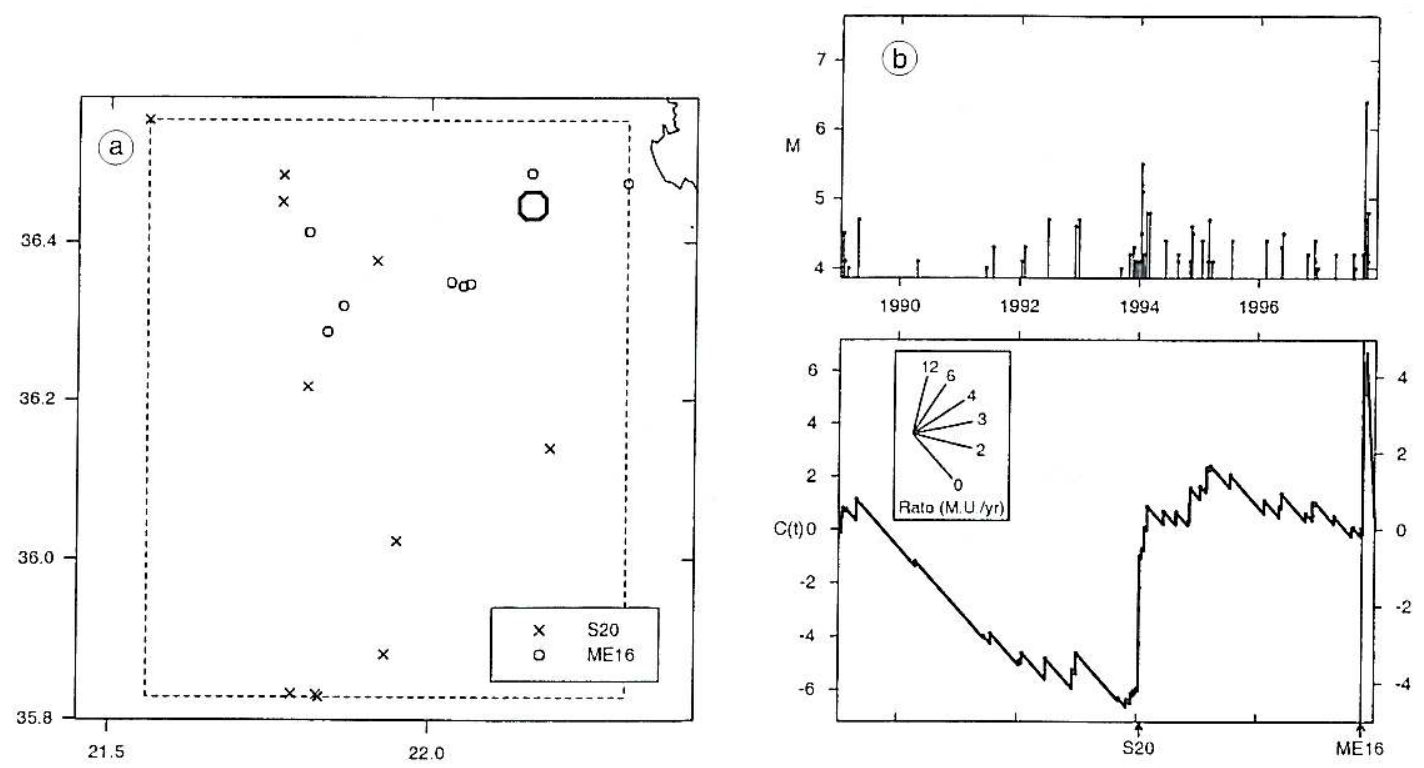

Fig. 2.8. Historical sequence Gj: Kithira. For explanation see caption fig. 2.1.

before and after are given in table $\mathrm{V}$ for each of the sequences in figs. 2.1-2.8. The ratio of the two seismicity rates is also given; the values range from 1.89 to 7.66 , with an average of 4.48 . An interpretation of this effect in terms of the seismogenic process will be given in Section 6 below.

The score-sheet of past events for Greece (table VI) shows the numbers of mainshock events and swarms (or swarm clusters) that were related through one of the precursory sequences in table IV; it also shows the numbers that were unrelated, despite having occurred at a suitable

Table VI. Score-sheet for past events.

\begin{tabular}{|c|c|c|}
\hline & Related & Unrelated \\
\hline & \multicolumn{2}{|c|}{ Mainshock events } \\
\hline$M_{n} \geq 6.5$ & 6 & 0 \\
\hline \multirow[t]{2}{*}{$6.4 \geq M_{m} \geq 6.2$} & 6 & 3 \\
\hline & \multicolumn{2}{|c|}{ Swarms or swarm cluster } \\
\hline$M_{p} \geq 5.0$ & 8 & 0 \\
\hline $4.9 \geq M_{p} \geq 4.5$ & 2 & 3 \\
\hline
\end{tabular}

time to have been related. Mainshock event ME 1 , which is the earliest multiple event to have been recognised in the catalogue, is considered too early for related swarms to have been recorded, and is excluded from the score-sheet. The swarms classed as unrelated are S 5, 9 and 11 , and the mainshocks classed as unrelated are ME 5, 10 and 12.

\section{Predictive correlations}

The data on precursory swarms and related mainshock events for Greece have been combined with the data from Japan and New Zealand to obtain well supported correlations. Differences between the three regions in respect of, for example, levels of seismicity, seismograph networks, and observatory procedures, have necessitated only minor algorithmic changes.

The correlation as regards location is as follows. The longitude $x$ and latitude $y$ of a mainshock epicentre is estimated from all the related swarm epicentres, weighted for magnitude, and assumed to follow a bivariate normal distribu- 
tion, with density given by

$$
\begin{gathered}
f(x, y)=\frac{1}{2 \pi \sigma_{x} \sigma_{y} \sqrt{1-\rho^{2}}} \cdot \\
\exp \left[\frac { - 1 } { 2 \sqrt { 1 - \rho ^ { 2 } } } \left(\frac{\left(x-\mu_{x}\right)^{2}}{\sigma_{x}^{2}}+\frac{\left(y-\mu_{y}\right)^{2}}{\sigma_{y}^{2}}-\right.\right. \\
\left.\left.-\frac{2 \rho\left(x-\mu_{x}\right)\left(y-\mu_{y}\right)}{\sigma_{x} \sigma_{y}}\right)\right]
\end{gathered}
$$

where $\mu_{1}$ and $\mu_{y}$ are the longitudinal and latitudinal means of the swarm epicentres, $\left(x-\mu_{x}\right)$, $\left(y-\mu_{y}\right)$ are in kilometres, and

$$
\begin{aligned}
& \sigma_{x}^{2}=a^{2}+b^{2} s_{x}^{2} \\
& \sigma_{y}^{2}=a^{2}+b^{2} s_{y}^{2}
\end{aligned}
$$

where $s_{x}, s_{v}$ are the standard deviations, and $\rho$ the correlation of the longitude and latitude of the swarm epicentres. The values $a=20 \mathrm{~km}$ and $b=1.1$ have been adopted for Greece, these being close to the maximum likelihood estimates. A more detailed explanation of this model has been given by Rhoades and Evison (1993). The parameter values for each historical sequence are given in table VII.

The largest mainshock in a sequence is called the principal mainshock, and the others (if any) are called secondary mainshocks. Figure 3 is a composite plot of the principal and secondary

Table VII. Historical sequences: spatial statistics.

\begin{tabular}{cccrrr}
\hline \hline Sequence & $\mu_{x}$ & $\mu_{y}$ & \multicolumn{1}{c}{$s_{x}$} & \multicolumn{1}{c}{$s_{y}$} & \multicolumn{1}{c}{$\rho$} \\
\hline $\mathrm{Ga}$ & 20.69 & 38.50 & 19.15 & 37.77 & -0.0612 \\
$\mathrm{~Gb}$ & 27.76 & 35.48 & 33.72 & 31.51 & 0.8029 \\
$\mathrm{Gc}$ & 20.87 & 37.43 & 23.61 & 12.95 & -0.2354 \\
$\mathrm{Gd}$ & 20.30 & 38.27 & 20.05 & 40.51 & 0.3877 \\
$\mathrm{Ge}$ & 20.90 & 37.19 & 15.42 & 11.49 & 0.2206 \\
$\mathrm{Gf}$ & 20.39 & 38.13 & 28.79 & 38.74 & 0.7460 \\
$\mathrm{Gg}$ & 21.00 & 37.69 & 19.14 & 22.44 & 0.0406 \\
$\mathrm{Gh}$ & 27.20 & 36.11 & 9.27 & 19.61 & -0.5329 \\
$\mathrm{Gi}$ & 22.09 & 38.18 & 28.13 & 16.37 & 0.6093 \\
$\mathrm{Gj}$ & 21.84 & 36.13 & 13.01 & 30.60 & -0.3604 \\
\hline
\end{tabular}

mainshock locations, normalised to the related swarms, for the 42 mainshock events in the combined New Zealand, Japan and Greece studies ( $c f$. Evison and Rhoades, 1998, fig. 1). It is apparent that the data for Greece fit the pattern.

The magnitudes and times of principal mainshocks are estimated from regressions of the combined historical data for Greece (table IV), New Zealand (Evison and Rhoades, 1993, table 5; Evison and Rhoades, 1997, table 5); and Japan (Evison and Rhoades, 1993, table 6; Evison and Rhoades, 1997, table 6). The regressions are as follows:

Principal mainshocks:

$$
\begin{aligned}
M_{m} & =3.098+0.673 M_{p}, \quad\left(\bar{R}^{2}=85.6 \%\right) \\
\log _{10} T_{p} & =1.253+0.404 M_{p}, \quad\left(\bar{R}^{2}=66.1 \%\right)
\end{aligned}
$$

where $T_{p}$ is in days, and $\bar{R}^{2}$ is the percentage of variance explained. The regressions are graphed in fig. 4. Magnitude uncertainty and other incidental variations contribute to the tolerance limits as shown. Again it is apparent that the data for Greece fit the patterns.

For secondary mainshocks, the distribution of magnitudes in a given sequence shows no clear pattern, and is assumed to be uniform on the interval $\left(M_{c}, M_{1}\right)$, where $M_{c}$ is the threshold magnitude for all mainshocks (i.e. $M_{r}=6.2$ ), and $M_{1}$ is the magnitude of the principal mainshock of the sequence. The distribution of precursor times $\left(T_{p}\right)$ is more widely scattered than that for principal mainshocks, and is assumed to follow a parallel relation to that in eq. (4.2). The number of secondary mainshocks in a sequence has also been found to vary with $M_{p}$ according to a generalised linear model. These relations are as follows:

Secondary mainshocks:

$$
\begin{aligned}
& \log _{10} T_{p}=1.171+0.404 M_{p} \\
& \ln \lambda=-10.375+1.688 M_{p}
\end{aligned}
$$

where $\lambda$ is the expected number of secondary mainshocks. $\lambda$ is subject to adjustment, by a Bayesian analysis, upwards if mainshocks occur, and downwards if they do not. 


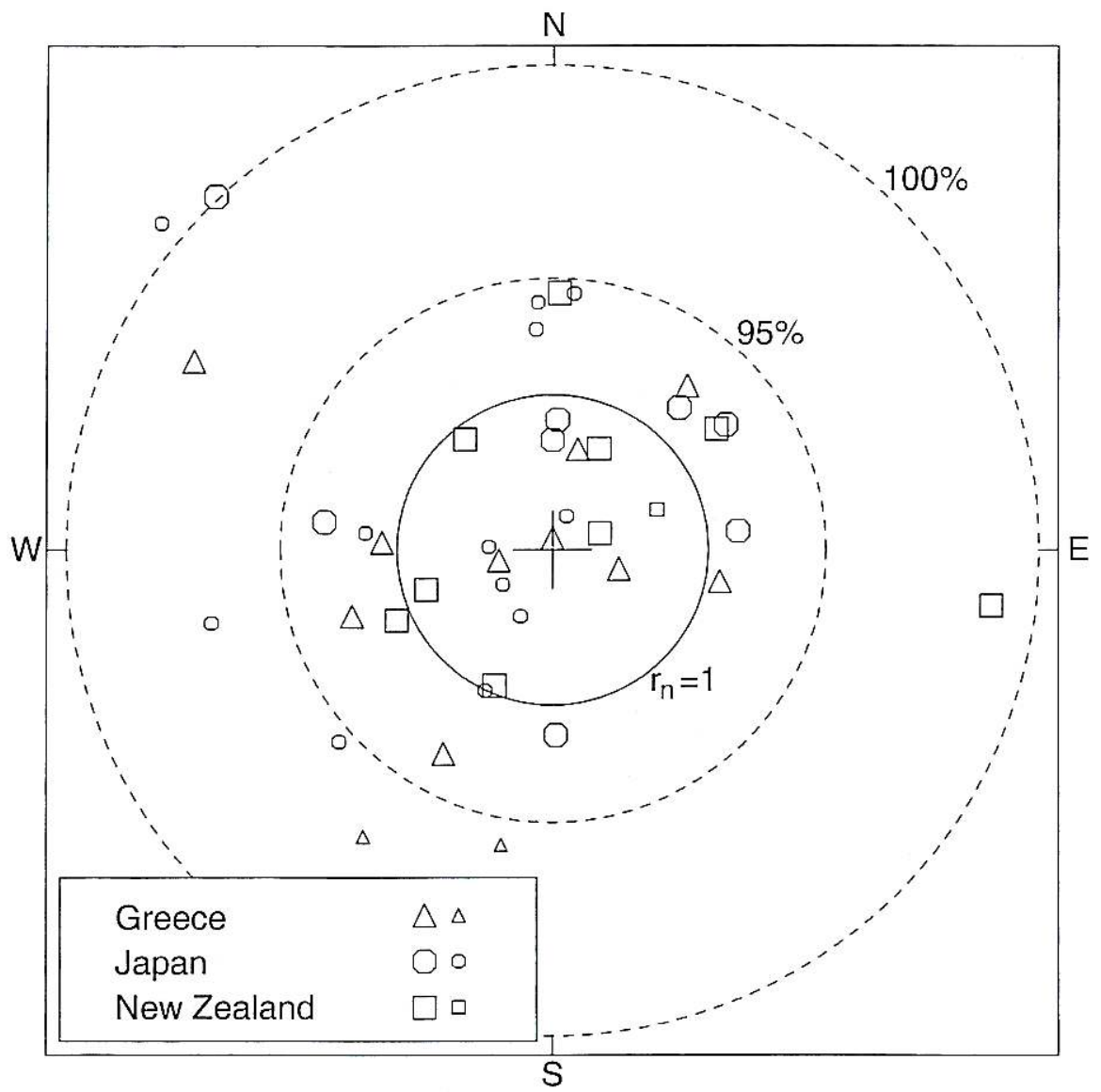

Fig. 3. Location of mainshocks relative to precursory swarms. The centre is the magnitude-weighted mean epicentre of the earthquakes in each cluster of swarms. The normalised radial distance is given by $r_{n}=r\left(s_{x}^{2}+s_{v}^{2}\right)^{-1 / 2}$, where $r$ is the radial distance, and $s_{\mathrm{r}}, s_{\mathrm{r}}$ are the magnitude-weighted standard deviations, in the W-E, N-S directions, respectively, of the related swarm epicentres. The scale of $r_{n}$ is shown by the inner (unit) circle. The dashed circles enclose $95 \%$ and $100 \%$, respectively, of all swarm earthquakes in the 28 historical sequences. Principal mainshocks are indicated by large symbols, and secondary mainshocks by small symbols. The dispersion of earthquakes in a cluster of swarms, measured by $\left(s_{x}^{2}+s_{v}^{2}\right)^{1 / 2}$, has varied, approximately with magnitude, from $19 \mathrm{~km}$ to $114 \mathrm{~km}$. The data from Greece are a good fit to the previous data from Japan and New Zealand.

\section{Stationary Poisson model}

Testing the hypothesis is achieved by using it to predict future mainshock events, and comparing its performance with that of the accepted present method of estimating earthquake hazard, i.e. the stationary Poisson model as applied to historical seismicity. The methodology has been given by Rhoades and Evison (1979, 1993). Historical seismicity is assumed to follow the standard Gutenberg-Richter relation:

$$
N(M)=N\left(M_{c}\right) 10^{-h\left(i t-M_{c}\right)}
$$

where $N(M)$ is the number of earthquakes of magnitude $M$ or greater, $M_{c}=6.2$ as stated above, and $b \approx 1$. 


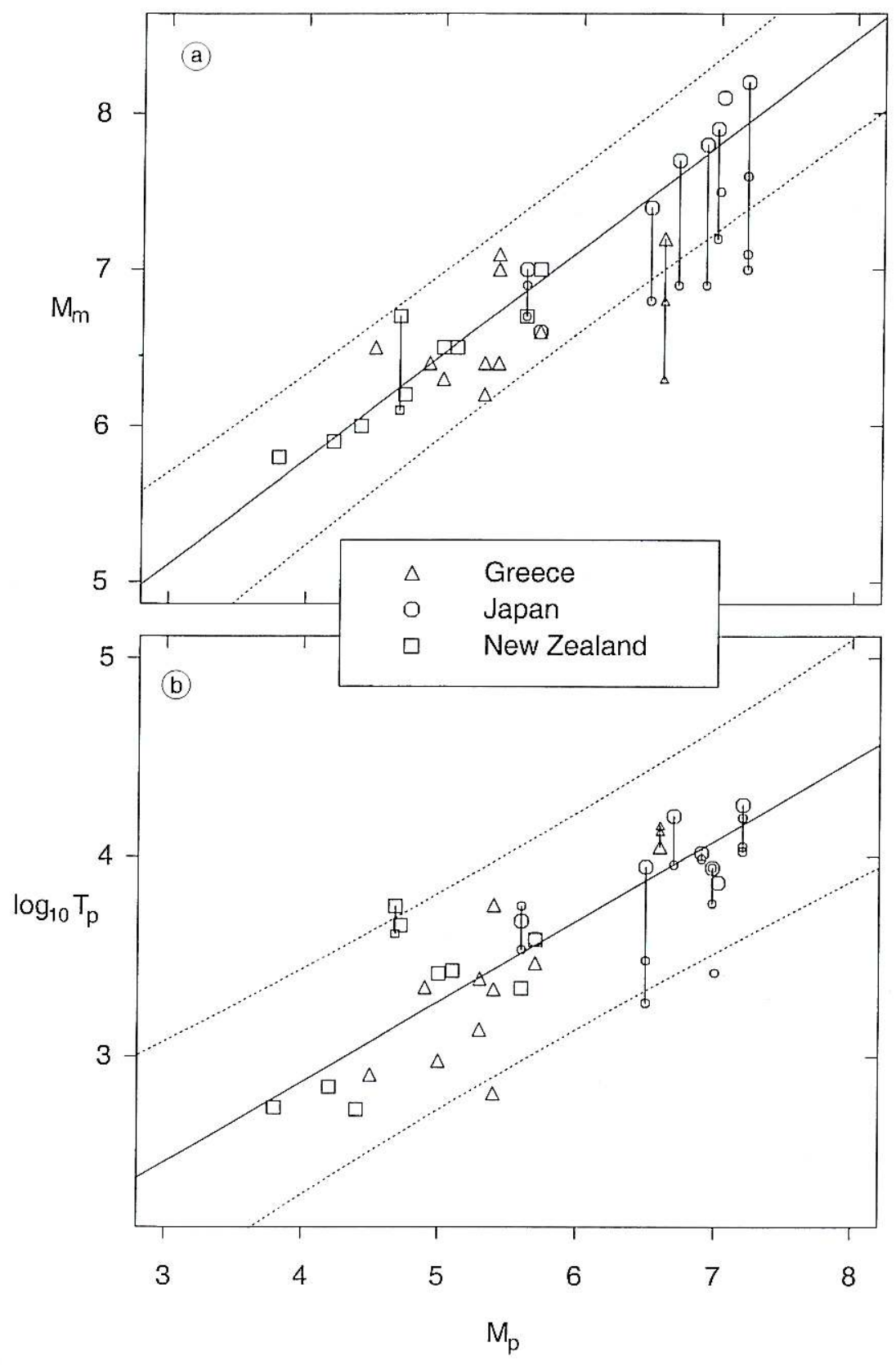

Fig. 4a,b. Relations between swarm magnitude, $M_{r}$, and (a) mainshock magnitude, $M_{m}$, (b) precursor time, $T_{p}$ (days). Large symbols represent principal mainshocks; small symbols represent secondary mainshocks, which are shown connected to the relevant principal mainshocks. The regressions (see eqs. (4.1) and (4.2)) are based on principal mainshocks only. Dotted curves show $95 \%$ tolerance limits. Again the data from Greece fit the previous data. 
In the region under surveillance in Greece, the value of $b$ for each seismogenic source has been estimated by Papazachos and Papazachou (1997, table 7.1), and from this the value of $N(6.2)$ has been obtained. The latter needs to be adjusted for the present purpose, since we are concerned only with earthquakes that are mainshocks as defined by the above recognition criteria. Thus we need to exclude earthquakes of magnitude $M \geq 6.2$ which occur in swarms or aftershock sequences, or not as part of a multiple event, e.g. earthquakes with too few aftershocks of magnitude $M \geq 4.0$ to satisfy the criteria for mainshock events. The adjustment is achieved by applying as a scaling factor the number of mainshock events in the whole re- gion of surveillance since 1970 (table I), divided by the corresponding number computed from Papazachos and Papazachou (1997). The resulting values are given in table VIII, together with the $b$-values, and the corner-coordinates of each seismogenic source area (fig. 1).

This or any assumed method of estimating historical seismicity is open to criticism, such are the limitations of available data. It is therefore worth pointing out that compensating effects render the present methodology somewhat insensitive to the particular values chosen for $N\left(M_{c}\right)$ and $b$ in eq. (5.1). The performance factor by which the hypothesis is assessed is the product of four likelihood ratios. These represent the occurrence and non-occurrence of predicted and

Table VIII. Data for Poisson model (after Papazachos and Papazachou, 1997).

\begin{tabular}{cccc}
\hline \hline $\begin{array}{c}\text { Seismogenic } \\
\text { source }\end{array}$ & \multicolumn{1}{c}{$\begin{array}{c}\text { Corners } \\
\text { (Lat., Long.) }\end{array}$} & $\begin{array}{c}N(6.2) \\
\left(\mathrm{eq} . / \mathrm{yr} / 10^{4} \mathrm{~km}^{2}\right)\end{array}$ & $b$ \\
\hline 6 & $39.1,20.438 .7,21.038 .2,20.038 .4,20.0$ & 0.03568 & 0.99 \\
7 & $38.7,21.038 .1,21.037 .8,20.438 .2,20.0$ & 0.07483 & 0.99 \\
8 & $38.1,21.038 .0,21.437 .4,20.837 .7,21.137 .8,20.4$ & 0.03490 & 0.99 \\
9 & $37.7,21.136 .8,22.136 .5,21.737 .4,20.8$ & 0.02738 & 0.98 \\
10 & $36.8,22.135 .5,23.435 .2,23.036 .5,21.7$ & 0.01396 & 0.97 \\
11 & $38.2,20.037 .4,20.837 .1,20.337 .7,19.7$ & 0.03065 & 1.02 \\
12 & $37.4,20.836 .5,21.736 .2,21.237 .1,20.3$ & 0.00761 & 1.00 \\
13 & $36.5,21.735 .2,23.035 .0,22.536 .2,21.2$ & 0.01251 & 0.99 \\
14 & $35.5,23.435 .1,24.534 .7,24.735 .2,23.0$ & 0.03106 & 0.98 \\
15 & $35.1,24.535 .1,26.434 .7,26.434 .7,24.7$ & 0.01371 & 1.00 \\
16 & $35.2,23.034 .7,24.734 .2,24.535 .0,22.5$ & 0.01754 & 0.99 \\
17 & $34.7,24.734 .7,26.434 .2,26.434 .2,24.5$ & 0.01370 & 1.01 \\
18 & $36.3,28.336 .1,28.634 .7,26.435 .1,26.4$ & 0.01552 & 0.96 \\
19 & $36.1,28.635 .7,29.034 .2,26.434 .7,26.4$ & 0.01428 & 0.97 \\
24 & $38.0,21.438 .0,22.437 .8,22.637 .1,22.336 .8,22.137 .7,21.1$ & 0.01618 & 0.95 \\
25 & $37.1,22.335 .9,23.635 .5,23.436 .8,22.1$ & 0.01815 & 0.96 \\
27 & $35.9,23.635 .5,24.735 .1,24.535 .5,23.4$ & 0.00407 & 0.96 \\
28 & $36.3,26.535 .1,26.435 .1,24.535 .5,24.7$ & 0.00859 & 0.98 \\
29 & $36.7,27.836 .3,28.335 .1,26.436 .3,26.5$ & 0.01258 & 0.95 \\
39 & $38.7,21.038 .5,22.838 .5,21.0$ & 0.01478 & 0.94 \\
42 & $38.5,21.038 .5,22.038 .0,22.038 .0,21.438 .1,21.0$ & 0.01688 & 0.96 \\
43 & $38.5,22.038 .5,22.838 .0,22.438 .0,22.0$ & 0.03524 & 0.93 \\
44 & $38.5,22.837 .8,22.638 .0,22.4$ & 0.03208 & 0.92 \\
48 & $37.1,27.336 .7,27.836 .3,26.5$ & 0.01488 & 0.92 \\
\hline
\end{tabular}


of unpredicted earthquakes (Rhoades and Evison, 1979). Now suppose, for example, that historical seismicity has been overestimated. Then the likelihood ratio for the occurrence of predicted mainshocks will be too small, while those for the non-occurrence of predicted and unpredicted mainshocks will both be too large. In the product, over the lengthy period of a test, the errors tend to compensate. It is nevertheless essential to the integrity of such tests that the chosen estimate of historical seismicity be stated at the outset.

\section{Seismogenic process}

The results from Greece add strength to the hypothesis that at shallow levels in subduction regions precursory swarms are closely related to mainshock events. This has been interpreted as meaning that the swarms are part of a long-term seismogenic process which culminates in the major earthquake (Evison and Rhoades, 1998). Further support for this interpretation has been found in a direct comparison between swarm magnitude $M_{p}$ (as defined above) and the analogous quantity, $M_{a}$, for the related aftershocks (Evison and Rhoades, 1998, fig. 3). The correlation between these quantities for the combined data from Greece, Japan and New Zealand is shown in fig. 5. The linear least-squares regression is given by

$$
M_{a}=1.42+0.75 M_{p}, \quad\left(\bar{R}^{2}=83.1 \%\right) .
$$

As with the parameters in figs. 3 and 4 , the data from Greece are a good fit to the previous data. The regression shows that swarms and aftershocks are closely correlated with respect to the largest magnitudes. It can also be seen that over the range of the observations these magnitudes are nearly equal. Thus in terms of the largest magnitudes, precursory swarms and aftershocks are about equally related to mainshocks.

In the proposed seismogenic process, a precursory increase in the level of seismicity is caused by the fracture of a set of minor cracks generated by a major crack, which itself fractures later to produce the mainshock. This increase in seismicity may take a variety of forms
(Evison and Rhoades, 1998). One of these is the precursory swarm. An effective triggering mechanism is evidently needed for a set of earthquakes to occur as a swarm, and at shallow levels in subduction regions this is attributed to the high level of fluid pressure which is a feature of such regions. The affinity of precursory swarms for subduction zones has been confirmed in Greece.

According to the seismogenic model, the precursory period of increased seismicity is also the period of mainshock seismogenesis. Thus the onset of seismogenesis is identified with that of the seismicity increase, as listed in table $\mathrm{V}$. In studies of seismicity changes, much attention has been given to the problem that such changes could be produced artificially, for example by changes in the seismograph network. This can be discounted in the present study, since the onset dates for the seismicity increase range from 1952.08.26 to 1993.10.29 (table V).

A different seismogenic model has been widely discussed to explain precursory increases in seismicity: the accelerating moment release model. In Greece, an early version of this model was proposed by Papadopoulos (1988b) to interpret increases of seismicity before several large earthquakes in the Western Hellenic arc region, and in one case to predict an earthquake of magnitude $M_{s}$ 6.2. More recently, the sequence culminating in the 1983 Kefallonia mainshock (table I, ME11; fig. 2.4) has been interpreted according to this model by Tzanis et al. (2000). In the latter work the lithosphere is assumed to be in a state of self-organized criticality (as in the present model), but the mainshock is treated as a critical-point phenomenon, and the precursory seismicity as displaying a power-law increase. In their fig. 2(B), Tzanis et al. show that the cumulative number of earthquakes occurring within a radius of $170 \mathrm{~km}$ from the Kefallonia mainshock epicentre was better fit by a power-law acceleration than a linear increase. It appears, however, that a bilinear increase, as required by the present model, would fit their data even better. In addition, the present model estimates the location of the mainshock to a much greater accuracy, and also estimates the magnitude.

A related question to that of the role of precursory swarms in seismogenesis is whether 


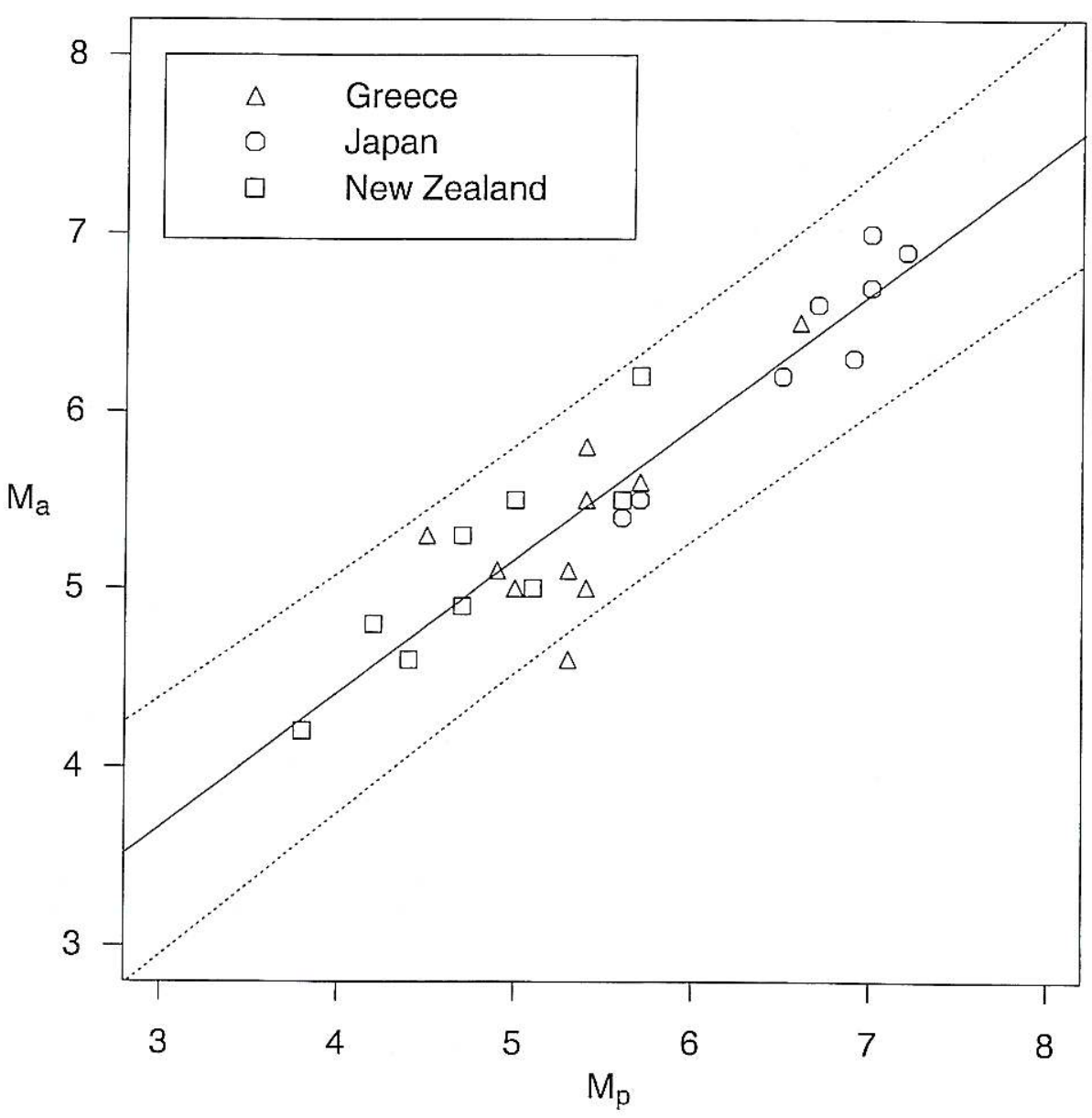

Fig. 5. Relation between swarm magnitude, $M_{r}$, and aftershock magnitude, $M_{i}$, (see eq. (6.1)). Dotted curves show $95 \%$ tolerance limits. Here too the data are in good agreement.

they may provide a means of synoptic earthquake forecasting. This is determined by carrying out formal hypothesis tests. Such tests, based on the above algorithm, have been started in Greece, and will be conducted in parallel with those already in progress in New Zealand and Japan (Evison and Rhoades, 1997, 1999). In each test, the performance of the hypothesis will be continually evaluated, and the significance of the end result will be assessed by the method of simulations (Evison and Rhoades, 1997).

\section{Conclusions}

The results of this study support the testing of the precursory swarm hypothesis in Greece. Tests will be carried out using the appropriate methodology (Rhoades and Evison, 1979, 1993), and in conformity with the UNESCO/IASPEI Code of Practice for Earthquake Prediction (IUGG, 1984). If the hypothesis performs sufficiently well it may provide a basis for longrange synoptic forecasting in the Hellenic arc region. 


\section{Acknowledgements}

This work was started during a visit by the first author to the Geophysical Laboratory, Aristotle University of Thessaloniki, at the invitation of Prof. B.C. Papazachos. The authors wish to thank Dr. E. Papadimitriou for providing many facilities and for arranging to make the AUTH catalogue available in advance of publication. Thanks are also extended to Dr. R. Robinson and Dr. W. D. Smith for critical readings of the manuscript. The work has been supported by the New Zealand Foundation for Research, Science and Technology, under Contract C05615. The first author acknowledges facilities provided under an Honorary Fellowship at Victoria University of Wellington.

\section{REFERENCES}

EVISON, F.F. and D.A. RHOADES (1993): The precursory earthquake swarm in New Zealand: hypothesis tests, N.Z. J. Geol. Geophys., 36, 51-60.

EvisON, F.F. and D.A. RHOADES (1997): The precursory earthquake swarm in New Zealand: hypothesis tests II, N. Z. J. Geol. Geophys., 40, 537-547.

EVISON, F.F. and D.A. RHOADES (1998): Long-term seismogenic process for major earthquakes in subduction zones, Phys. Earth Planet. Inter, 108, 185-199.

Evison, F.F. and D.A. RHOADES (1999): The precursory earthquake swarm in Japan: hypothesis test, Earth Planet. Space, 51, 1267-1277.

IUGG (1984): Code of practice for earthquake prediction, IUGG Chronicle, 65, 27-28.

KANAMORI, H. (1981): The nature of seismicity patterns before large earthquakes, in Earthquake Prediction, an International Review, edited by D.W. SIMPSON and P.G. Richards, Am. Geophys. Un., 1-19.
Mikumo, T. and T. Miyatake (1983): Numerical modelling of space and time variations of seismic activity before major earthquakes, Geophys. J. R. Astron. Soc., $74,559-583$.

MoGi, K. (1963): Some discussions on aftershocks, foreshocks and earthquake swarms- the fracture of a semiinfinite body caused by an inner stress origin and its relation to the earthquake phenomena, Bull. Earthquake Res. Inst., 41, 615-658.

PAPADOPOULOS, G.A. (1988a): Premonitory burst of seismicity and its significance for predicting large Aegean earthquakes, Tectonophysics, 156, 257-265.

PAPADOPOULOS, G.A. (1988b): Long-term accelerating foreshock activity may indicate the occurrence time of a strong shock in the Western Hellenic arc, Tectonophysics, 152, 179-192.

PAPAZACHOS, B. and C. PAPAZACHOU (1997): The Earthquakes of Greece (P. Ziti \& Co., Thessaloniki), pp. 304.

RHOADES, D.A. and F.F. EvisON (1979): Long-range earthquake forecasting based on a single predictor, Geophys. J. R. Astron. Soc., 59, 43-56.

RHOADES, D.A. and F.F. Evison (1993): Long-range earthquake forecasting based on a single predictor with clustering, Geophys. J. Int., 113, 371-381.

RIKITAKE, T. (1979): Classification of earthquake precursors, Tectonophysics, 54, 293-309.

TZANIS, A., F. VALliANATOS and K. MAKROPOULOS (2000): Seismic and electrical precursors to the 17-1-1983, M7 Kefallinia earthquake, Greece: signatures of a SOC system, Phys. Chem. Earth, 25, 281-287.

WYSS, M., K. SHIMAZAKI and A. ITO (Editors) (1999): Seismicity patterns, their statistical significance and physical meaning, Pure Appl. Geoplys., 155 (special issue), 203-726.

YAMASHITA, T. and L. KNOPOFF (1992): Model for intermediate-term precursory clustering of earthquakes, J. Geophys. Res., 97, 19873-19879.

(received May 24, 2000; accepted September 28, 2000) 